\title{
PLANT NOTES
}

\section{LONG-HEADED CONE-FLOWER}

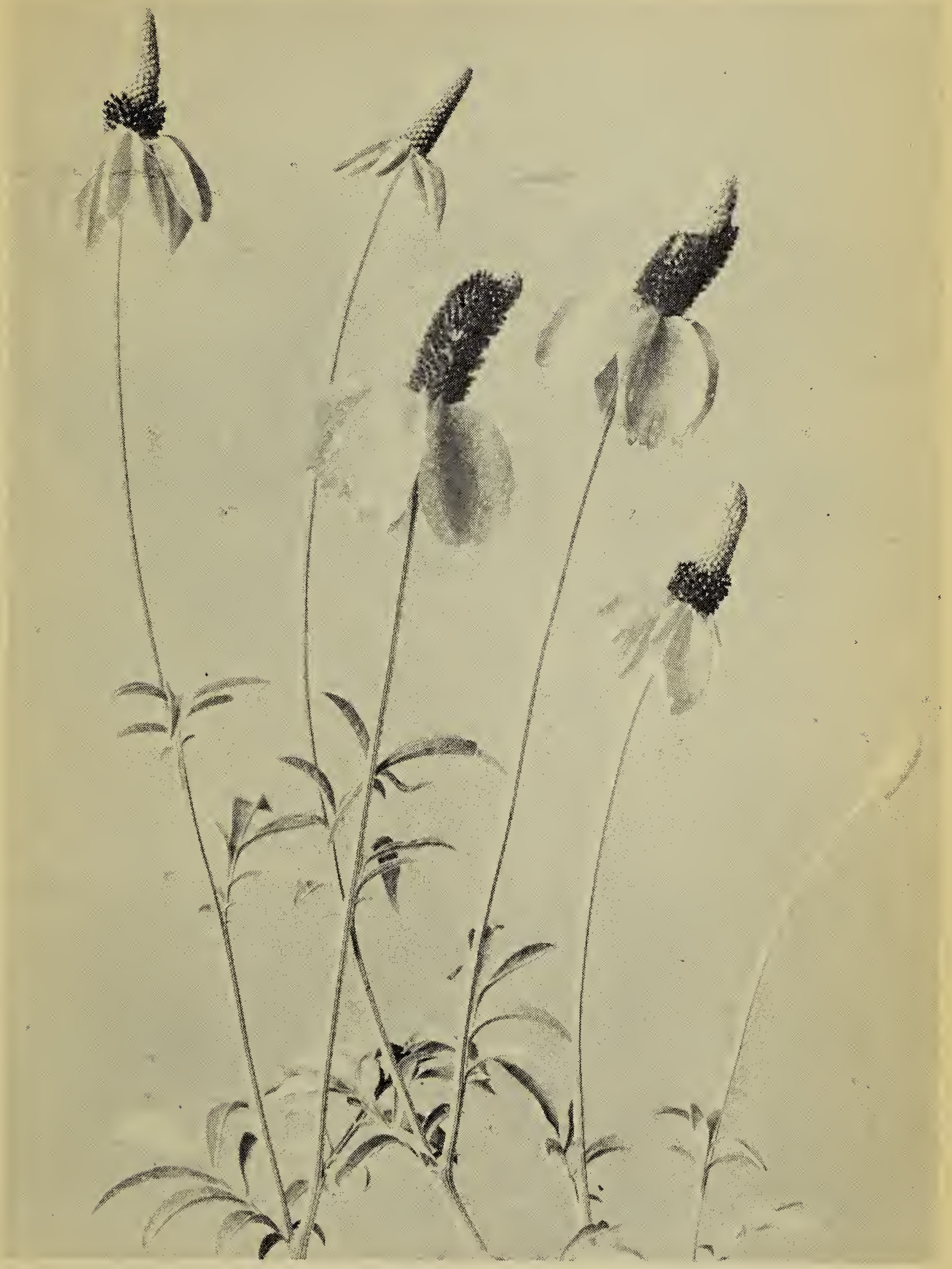

Long-headed Cone-flower

Photo by W. C. McCalla

Ratibida columnifera (Nutt.) Wooton \& Standl.

The Cone-flower occurs in the three prairie provinces and south to Mexico. The rays are usually golden. Sometimes plants are found in which the rays are a rich brownish-purple and these plants are placedi in the variety pulcherrima, meaning that they are very handsome. 